\title{
Gravitational separation in the stratosphere - a new indicator of atmospheric circulation
}

\author{
S. Ishidoya ${ }^{1}$, S. Sugawara ${ }^{2}$, S. Morimoto ${ }^{3}$, S. Aoki ${ }^{4}$, T. Nakazawa ${ }^{4}$, H. Honda ${ }^{5}$, and S. Murayama ${ }^{1}$ \\ ${ }^{1}$ National Institute of Advanced Industrial Science and Technology (AIST), Tsukuba 305-8569, Japan \\ ${ }^{2}$ Miyagi University of Education, Sendai 980-0845, Japan \\ ${ }^{3}$ National Institute of Polar Research, Tokyo 190-8518, Japan \\ ${ }^{4}$ Center for Atmospheric and Oceanic Studies, Tohoku University, Sendai 980-8578, Japan \\ ${ }^{5}$ Institute of Space and Astronautical Science (ISAS), Japan Aerospace Exploration Agency (JAXA), \\ Sagamihara 252-5210, Japan
}

Correspondence to: S. Ishidoya (s-ishidoya@aist.go.jp)

Received: 30 December 2012 - Published in Atmos. Chem. Phys. Discuss.: 20 February 2013

Revised: 23 July 2013 - Accepted: 23 July 2013 - Published: 3 September 2013

\begin{abstract}
As a basic understanding of the dynamics of the atmospheric circulation, it has been believed that gravitational separation of atmospheric components is observable only in the atmosphere above the turbopause. However, we found, from our high-precision measurements of not only the isotopic ratios of $\mathrm{N}_{2}, \mathrm{O}_{2}$ and $\mathrm{Ar}$ but also the mole fraction of $\mathrm{Ar}$, that gravitational separation occurs even in the stratosphere below the turbopause; their observed vertical profiles are in good agreement with those expected theoretically from molecular mass differences. The $\mathrm{O}_{2} / \mathrm{N}_{2}$ ratio observed in the middle stratosphere, corrected for gravitational separation, showed the same mean air age as estimated from the $\mathrm{CO}_{2}$ mole fraction. Simulations with a 2-dimensional model of the middle atmosphere indicated that a relationship between gravitational separation and the age of air in the stratosphere would be significantly affected if the Brewer-Dobson circulation was enhanced due to global warming. Therefore, gravitational separation is usable as a new indicator of changes in the atmospheric circulation in the stratosphere.
\end{abstract}

\section{Introduction}

The gravity of the earth prevents the atmosphere from dissipating into space. It is also known that the gravity causes atmospheric molecules to separate depending on their molar masses, which is called "gravitational separation". It is widely recognized that gravitational separation of atmo- spheric components occurs in the atmosphere above the turbopause (about $100 \mathrm{~km}$ ) (Lewis and Prinn, 1984; Jacobs, 1999). On the other hand, we have suggested from our measurements of the stable isotopic ratios of major atmospheric components $\left(\delta\left({ }^{15} \mathrm{~N}\right)\right.$ of $\mathrm{N}_{2}$ and $\delta\left({ }^{18} \mathrm{O}\right)$ of $\left.\mathrm{O}_{2}\right)$ (Ishidoya et al., 2006, 2008a, b) that gravitational separation exists even in the stratosphere. However, in our earlier studies, we were not able to exclude the possibility that some other factors affected our measurement results.

In this paper, we present new concrete evidence for the existence of gravitational separation in the stratosphere. We also show a significant effect of gravitational separation on the $\mathrm{O}_{2} / \mathrm{N}_{2}$ ratio $\left(\delta\left(\mathrm{O}_{2} / \mathrm{N}_{2}\right)\right)$ measured in the stratosphere. Furthermore, we propose to use gravitational separation as a new indicator to detect a change in the Brewer-Dobson Circulation (BDC) (Brewer, 1949) in the stratosphere. Atmospheric general circulation models have shown that the mean age of stratospheric air decreases as the BDC is enhanced under global warming (Austin and Li, 2006; Li et al., 2008), but a significant change of the air age has not been observed so far (Engel et al., 2009). Since the gravitational separation occurs physically due to gravity, its effect is expected to become more pronounced as the stratospheric air is slowly transported poleward after it enters the tropical stratosphere from the troposphere. Therefore, in this conceptual framework, by measuring gravitational separation, it would be possible to obtain information about changes in the stratospheric circulation. To confirm this supposition, we simulate 
stratospheric gravitational separation using a 2-dimensional model of the middle atmosphere (SOCRATES) (Huang et al. 1998; Park et al., 1999; Khosravi et al., 2002), and then examine the relationship between gravitational separation and the stratospheric circulation.

\section{Stratospheric air collection and sample analyses}

The collection of stratospheric air has been carried out using a balloon-borne cryogenic air sampler over Sanriku $\left(39^{\circ} \mathrm{N}\right.$, $142^{\circ} \mathrm{E}$ ) and Taiki $\left(43^{\circ} \mathrm{N}, 143^{\circ} \mathrm{E}\right)$, Japan, since 1985 (e.g., Nakazawa et al., 1995; Aoki et al., 2003). Our air sampler consists of 12 stainless-steel sample containers, a liquid helium dewar, a receiver, a transmitter, a control unit and batteries; all these components are housed in a water- and pressureproof aluminum chamber (Honda, 1990; Honda et al., 1996). The volume of each sample container is about $760 \mathrm{~mL}$, and its inner wall is electropolished. A motor-driven metal-tometal seal valve is attached to each sample container. The other end of the motor-driven valve is connected to a sample intake, located $3.5 \mathrm{~m}$ below the bottom of the aluminum chamber, through a manifold and a stainless-steel bellows tube with an inner diameter of $15 \mathrm{~mm}$ reinforced with mesh. Before sampling, all the sample containers were evacuated by heating and then cooled by filling the dewar with liquid He. Then, the cryogenic air sampler was connected to a large balloon, launched from the balloon center at Sanriku or Taiki early in the morning and recovered from the Pacific Ocean around noon. Air samples were collected in the containers at assigned altitudes by opening and closing the motor-driven valves using a telecommand system. The flow rates of sample air at the respective altitudes were $50-100 \mathrm{~L} \mathrm{~min}^{-1}$ at ambient pressures, and typical amounts of air samples collected were about $25 \mathrm{~L}$ at standard temperature $\left(0^{\circ} \mathrm{C}\right)$ and pressure $(1013.25 \mathrm{hPa})$.

In this study, $\delta\left({ }^{15} \mathrm{~N}\right)$ of $\mathrm{N}_{2}, \delta\left({ }^{18} \mathrm{O}\right)$ of $\mathrm{O}_{2}, \delta\left(\mathrm{O}_{2} / \mathrm{N}_{2}\right)$, $\delta\left(\operatorname{Ar} / \mathrm{N}_{2}\right)$ and $\delta\left({ }^{40} \mathrm{Ar}\right)$ are reported in per meg (one per meg is equal to $1 \times 10^{-6}$ ),

$$
\begin{aligned}
& \delta\left({ }^{15} \mathrm{~N}\right)=\frac{\left[n\left({ }^{15} \mathrm{~N}^{14} \mathrm{~N}\right) / n\left({ }^{14} \mathrm{~N}^{14} \mathrm{~N}\right)\right]_{\text {sample }}}{\left[n\left({ }^{15} \mathrm{~N}^{14} \mathrm{~N}\right) / n\left({ }^{14} \mathrm{~N}^{14} \mathrm{~N}\right)\right]_{\text {reference }}}-1, \\
& \delta\left({ }^{18} \mathrm{O}\right)=\frac{\left[n\left({ }^{18} \mathrm{O}^{16} \mathrm{O}\right) / n\left({ }^{16} \mathrm{O}^{16} \mathrm{O}\right)\right]_{\text {sample }}}{\left[n\left({ }^{18} \mathrm{O}^{16} \mathrm{O}\right) / n\left({ }^{16} \mathrm{O}^{16} \mathrm{O}\right)\right]_{\text {reference }}}-1, \\
& \delta\left(\mathrm{O}_{2} / \mathrm{N}_{2}\right)=\frac{\left[n\left({ }^{16} \mathrm{O}^{16} \mathrm{O}\right) / n\left({ }^{15} \mathrm{~N}^{14} \mathrm{~N}\right)\right]_{\text {sample }}}{\left[n\left({ }^{16} \mathrm{O}^{16} \mathrm{O}\right) / n\left({ }^{15} \mathrm{~N}^{14} \mathrm{~N}\right)\right]_{\text {reference }}}-1, \\
& \delta\left(\mathrm{Ar} / \mathrm{N}_{2}\right)=\frac{\left[n\left({ }^{40} \mathrm{Ar}\right) / n\left({ }^{14} \mathrm{~N}^{14} \mathrm{~N}\right)\right]_{\text {sample }}}{\left[n\left({ }^{40} \mathrm{Ar}\right) / n\left({ }^{14} \mathrm{~N}^{14} \mathrm{~N}\right)\right]_{\text {reference }}}-1,
\end{aligned}
$$

and

$$
\delta\left({ }^{40} \mathrm{Ar}\right)=\frac{\left[n\left({ }^{40} \mathrm{Ar}\right) / n\left({ }^{36} \mathrm{Ar}\right)\right]_{\text {sample }}}{\left[n\left({ }^{40} \mathrm{Ar}\right) / n\left({ }^{36} \mathrm{Ar}\right)\right]_{\text {reference }}}-1 .
$$

Here, $n$ means the amount of each substance, and "reference" is dried natural air filled in a high-pressure cylinder in the suburban areas of Sendai $\left(38^{\circ} \mathrm{N}, 140^{\circ} \mathrm{E}, 150 \mathrm{~m}\right.$ a.s.l. $)$, Japan, in November 1998 as a primary standard of our measurements (Ishidoya et al., 2003). We have also prepared 6 working standard air by a similar procedure, and the working standards showed no systematic trend in the $\delta\left({ }^{15} \mathrm{~N}\right), \delta\left({ }^{18} \mathrm{O}\right)$ and $\delta\left(\mathrm{O}_{2} / \mathrm{N}_{2}\right)$ with respect to the primary standard since 1999 (Ishidoya et al., 2012). To detect gravitational separation in the stratosphere, we measured the $\delta\left({ }^{15} \mathrm{~N}\right)$ of $\mathrm{N}_{2}, \delta\left({ }^{18} \mathrm{O}\right)$ of $\mathrm{O}_{2}$ and $\delta\left(\mathrm{O}_{2} / \mathrm{N}_{2}\right)$ of the air samples collected over Sanriku on 31 May 1999, 28 August 2000, 30 May 2001, 4 September 2002, 6 September 2004, 3 June 2006 and 4 June 2007, as well as of those collected over Taiki on 22 August 2010, using a mass spectrometer (Finnigan MAT-252) (Ishidoya et al., 2003). $\delta\left({ }^{15} \mathrm{~N}\right)$ of $\mathrm{N}_{2}$ and $\delta\left({ }^{18} \mathrm{O}\right)$ of $\mathrm{O}_{2}$ were also measured for the samples collected over Sanriku on 8 June 1995. Furthermore, the air samples collected over Sanriku on 4 June 2007 were analyzed for $\delta\left({ }^{15} \mathrm{~N}\right)$ of $\mathrm{N}_{2}, \delta\left({ }^{18} \mathrm{O}\right)$ of $\mathrm{O}_{2}$, $\delta\left(\mathrm{O}_{2} / \mathrm{N}_{2}\right), \delta\left(\mathrm{Ar} / \mathrm{N}_{2}\right)$ and $\delta\left({ }^{40} \mathrm{Ar}\right)$ using a new mass spectrometer (Thermo Scientific DELTA-V). It is noted that the $\delta\left({ }^{15} \mathrm{~N}\right)$ and $\delta\left({ }^{18} \mathrm{O}\right)$ values measured by using the MAT-252 are confirmed to agree with those measured by DELTA- $V$ within the measurement precision, as seen in Fig. 1 discussed below. The measurement precision (external reproducibility) of MAT-252 for $\delta\left(\mathrm{O}_{2} / \mathrm{N}_{2}\right), \delta\left({ }^{15} \mathrm{~N}\right)$ and $\delta\left({ }^{18} \mathrm{O}\right)$ of the stratospheric air samples was estimated to be $\pm 30-40, \pm 12$ and \pm 26 per meg $( \pm 1 \sigma)$, respectively, by repeatedly introducing the same air sample into the mass spectrometer (Ishidoya et al., 2006). On the other hand, DELTA-V showed a precision of $\pm 5, \pm 7, \pm 35$ and \pm 22 per meg for $\delta\left({ }^{15} \mathrm{~N}\right)$ of $\mathrm{N}_{2}, \delta\left({ }^{18} \mathrm{O}\right)$ of $\mathrm{O}_{2}, \delta\left(\mathrm{Ar} / \mathrm{N}_{2}\right)$ and $\delta\left({ }^{40} \mathrm{Ar}\right)$, respectively.

\section{Results and discussion}

\subsection{Vertical profiles of the isotopic ratios of $\mathrm{N}_{2}, \mathrm{O}_{2}$ and $A r$, and the $A r / N_{2}$ ratio}

Figure 1 shows the vertical profiles of the isotopic ratios of $\mathrm{N}_{2}, \mathrm{O}_{2}$, and $\mathrm{Ar}$, and the $\mathrm{Ar} / \mathrm{N}_{2}$ ratio over Sanriku on 4 July 2007. Since the differences in mass number $(\Delta m)$ for $\delta\left({ }^{18} \mathrm{O}\right)$, $\delta\left(\mathrm{Ar} / \mathrm{N}_{2}\right)$ and $\delta\left({ }^{40} \mathrm{Ar}\right)$ are 2,12 and 4 , respectively, the measured values of each variable plotted in this figure are normalized to the values corresponding to $\Delta m=1$, i.e., $\delta\left({ }^{18} \mathrm{O}\right) / 2$, $\delta\left(\mathrm{Ar} / \mathrm{N}_{2}\right) / 12$ and $\delta\left({ }^{40} \mathrm{Ar}\right) / 4$. The measured values are also summarized in the electronic supplement, Table S1. As seen in Fig. 1, all the vertical profiles show a gradual decrease with height, their average difference between the lowermost part of the stratosphere and $32 \mathrm{~km}$ being about 45 per meg, and the fluctuations of their profiles are correlated well with each 


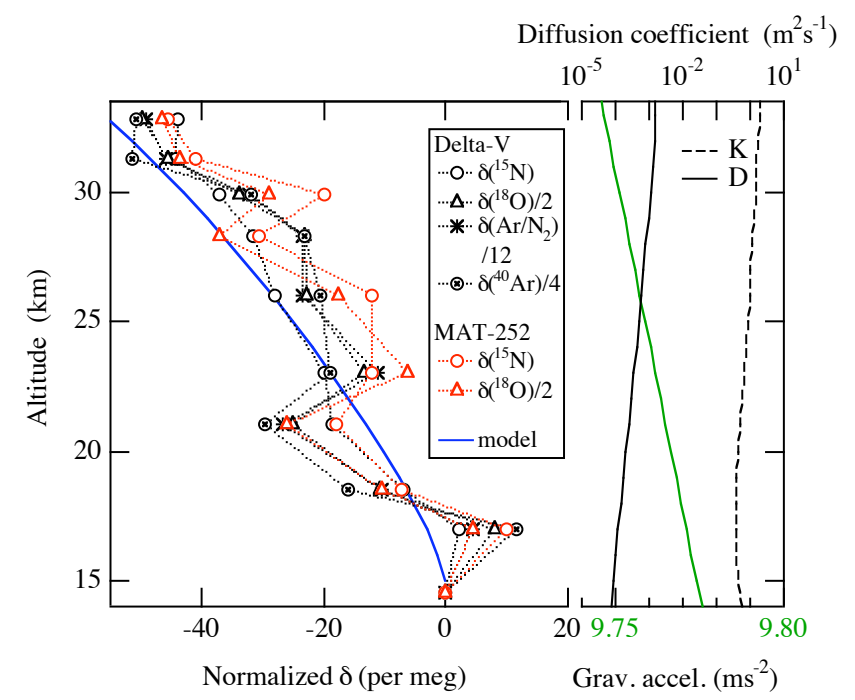

Fig. 1. $\delta\left({ }^{15} \mathrm{~N}\right)$ of $\mathrm{N}_{2}, \delta\left({ }^{18} \mathrm{O}\right) / 2$ of $\mathrm{O}_{2}, \delta\left(\mathrm{Ar} / \mathrm{N}_{2}\right) / 12$ and $\delta\left({ }^{40} \mathrm{Ar}\right) / 4$ observed over Sanriku, Japan, on 4 July 2007. Also shown is the vertical profile of $\delta$ value calculated using a 1-dimensional steady state eddy diffusion/molecular diffusion model for the mass number difference of 1 . The tropopause height on 4 July 2007 was estimated to be about $12 \mathrm{~km}$. The vertical eddy diffusion coefficient (black dashed line) and molecular diffusion coefficient (black solid line), and the gravitational acceleration (green solid line) for the model are also shown.

other. Such a good correlation is not well interpreted yet, but causes may be seasonally varying strength of the BDC or short-term variations in the stratospheric air transport. A vertical profile calculated using a 1-dimensional steady state eddy diffusion/molecular diffusion model for $\Delta m=1$ is also shown in Fig. 1. The model is based on Eq. (33) in Lettau (1951),

$C_{i}=$

$C_{i 0} \exp \left(-\frac{\mu_{i}}{H} \int_{0}^{z} \frac{g T_{0}}{g_{0} T} Q_{i} d z\right)\left[1-\frac{\gamma_{0}}{C_{i 0}} \int_{0}^{z} \frac{Q_{i}}{N D_{i \mathrm{~N}_{2}}} \exp \left(\frac{\mu_{i}}{H} \int_{0}^{z} \frac{g T_{0}}{g_{0} T} Q_{i} d z\right) d z\right]$,

$Q_{i}=\frac{D_{i \mathrm{~N}_{2}}}{D_{i \mathrm{~N}_{2}}+K_{z}}$

$\mu_{i}=\left(m_{i}-m_{\mathrm{N}_{2}}\right) / m_{\mathrm{N}_{2}}$,

and

$H=k T_{0} / m_{\mathrm{N}_{2}} g_{0}$,

where subscript $i$ denotes the species of air. $C_{i}, g$ and $T$ are the number density, the gravitational acceleration and absolute temperature at the altitude $z \mathrm{~km}$, respectively. The index " 0 " (e.g., $C_{i 0}$ ) refers to the quantities at the Earth's surface. $g_{0}$ is $9.8 \mathrm{~ms}^{-2}$ and the vertical profile of $g$ is also shown in
Fig. 1. $N$ is the number density of air, and $\gamma_{0}$ is the strength of the continuous external source (or sink). The $\gamma_{0}$ is simply assumed to be zero in this study. $H$ and $\mu_{i}$ denote the scale height and the reduced mass, respectively. $m_{i}$ and $m_{\mathrm{N}_{2}}$ are the relative molecular masses of the species $i$ and $\mathrm{N}_{2}$, respectively. $k$ is Boltzmann's constant, and $D_{i \mathrm{~N}_{2}}$ and $K_{z}$ denote the coefficient of mutual ( $i$ and $\mathrm{N}_{2}$ ) molecular diffusion and the vertical eddy diffusion coefficient, respectively. The vertical eddy diffusion and molecular diffusion coefficients for the model were taken from Massie and Hunten (1981) and Lettau (1951), respectively, and the coefficients were also plotted in Fig. 1. Atmospheric temperatures and pressures of the model were given by the meteorological data obtained from rawinsonde observations. The calculated vertical profile is highly consistent with the observational results, suggesting that gravitational separation due to molecular diffusion can occur even in the stratosphere. However, as pointed out in our previous studies (Ishidoya et al., 2006, 2008a), the air intake of our cryogenic air sampler is gradually heated by the solar radiation during ascent, possibly causing lighter molecules to enter the sample air preferentially at high altitudes by a process called thermal diffusion (Blaine et al., 2006). If this is the case, such an effect would yield a vertical profile similar to that expected from the gravitational separation. Therefore, for providing a definitive evidence of the existence of gravitational separation in the stratosphere, it is indispensable to quantitatively evaluate the magnitude of the thermal diffusion effect. It is noted that the thermal diffusion could also cause a diffusive separation of the actual lower atmosphere in the center of a wide desert due to the nighttime vertical temperature gradient (Adachi et al., 2006).

\subsection{Laboratory experiments on the thermal diffusion effect}

To examine the thermal diffusion effect at the air intake, laboratory experiments were carried out. Dry natural air was first filled into two $2700 \mathrm{~mL}$ Pyrex glass flasks connected in series at an overpressure of $0.07 \mathrm{MPa}$, and then one was gradually cooled to $-57^{\circ} \mathrm{C}$, while the other was kept at room temperature $\left(25^{\circ} \mathrm{C}\right)$. During this period, the air in the flask with room temperature was introduced into an inlet system of the mass spectrometer equipped with a dual inlet system (Thermo Scientific DELTA-V). The sample air introduced from the flask was exhausted from the inlet system with a flow rate of $4 \mathrm{~mL} \min ^{-1}$ and only a smidgen of air was transferred to an ion source of the mass spectrometer through a thermally insulated fused silica capillary, to continuously measure $\delta\left({ }^{15} \mathrm{~N}\right), \delta\left({ }^{18} \mathrm{O}\right), \delta\left(\mathrm{O}_{2} / \mathrm{N}_{2}\right), \delta\left(\mathrm{Ar} / \mathrm{N}_{2}\right)$ and $\delta\left({ }^{40} \mathrm{Ar}\right)$. The reference air was also introduced into the mass spectrometer by the same procedure using the other inlet. The pressure imbalance between the sample air and the reference air as well as the influences of $\mathrm{CO}_{2}$ mole fraction and $\mathrm{O}_{2} / \mathrm{N}_{2}$ ratio of the sample air on the measured values of the respective variables were experimentally corrected (e.g., Bender et 


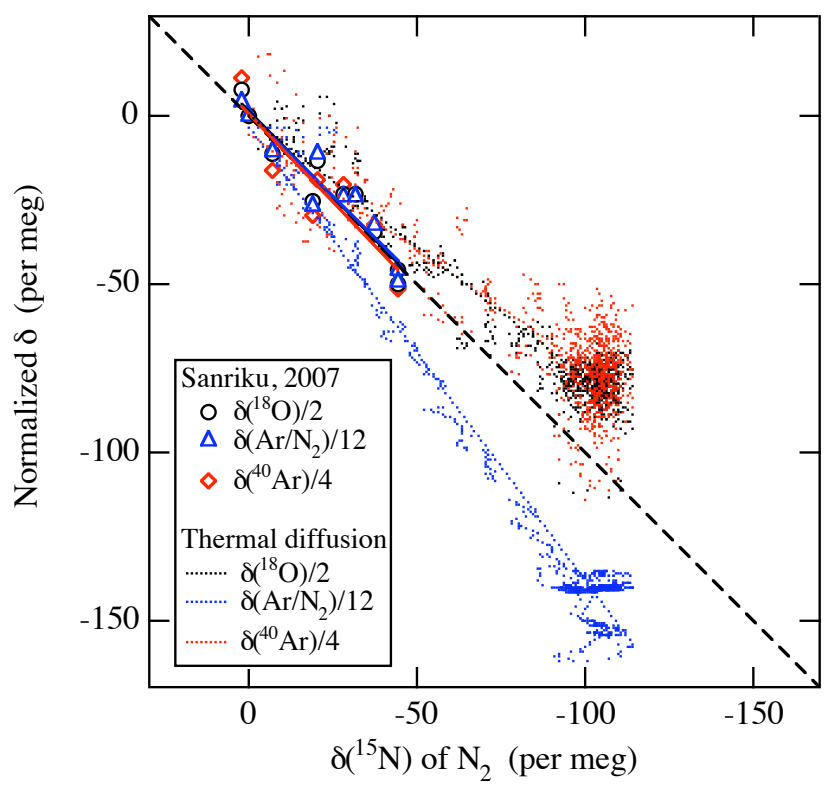

Fig. 2. Plots of $\delta\left({ }^{18} \mathrm{O}\right) / 2, \delta\left(\mathrm{Ar} / \mathrm{N}_{2}\right) / 12$ and $\delta\left({ }^{40} \mathrm{Ar}\right) / 4$ against $\delta\left({ }^{15} \mathrm{~N}\right)$ for stratospheric air samples collected over Sanriku, Japan, on 4 July 2007, and those for laboratory experiments to examine a possible effect of thermal diffusion at the air intake of the sampler on the collected air samples (see text). Black dashed line represents the relationship expected from the gravitational separation.

al., 1994; Ishidoya et al., 2003). The sample air and the reference air were alternately analyzed, taking $80 \mathrm{~s}$ for one cycle analysis of reference-sample-reference. By analyzing the same air sample repeatedly, the precision of measured values of $\delta\left({ }^{15} \mathrm{~N}\right), \delta\left({ }^{18} \mathrm{O}\right), \delta\left(\mathrm{O}_{2} / \mathrm{N}_{2}\right), \delta\left(\mathrm{Ar} / \mathrm{N}_{2}\right)$ and $\delta\left({ }^{40} \mathrm{Ar}\right)$ was estimated to be $\pm 8, \pm 20, \pm 5, \pm 10$ and \pm 70 per meg, respectively.

In general, gravitational separation is completely massdependent (proportional to the difference between the mass numbers of related molecules), while the fractionation of molecules due to thermal diffusion is slightly mass-independent (Severinghaus et al., 2001). The relationships of $\delta\left({ }^{18} \mathrm{O}\right) / 2, \delta\left(\mathrm{Ar} / \mathrm{N}_{2}\right) / 12$ and $\delta\left({ }^{40} \mathrm{Ar}\right) / 4$ with $\delta\left({ }^{15} \mathrm{~N}\right)$ of $\mathrm{N}_{2}$, obtained from our laboratory experiments, are shown in Fig. 2 together with those observed in the stratosphere. The experimentally determined ratios of $\delta\left({ }^{18} \mathrm{O}\right) / \delta\left({ }^{15} \mathrm{~N}\right), \delta\left(\mathrm{Ar} / \mathrm{N}_{2}\right) / \delta\left({ }^{15} \mathrm{~N}\right)$ and $\delta\left({ }^{40} \mathrm{Ar}\right) / \delta\left({ }^{15} \mathrm{~N}\right)$ are $(1.55 \pm 0.02),(16.2 \pm 0.1)$ and $(2.75 \pm 0.05)$ per meg per $\mathrm{meg}^{-1}$, respectively. These ratios are clearly different from the corresponding values of $(2.1 \pm 0.2),(11.9 \pm 1.4)$ and $(4.2 \pm 0.6)$ per meg per $\mathrm{meg}^{-1}$ derived from the observational results shown in Fig. 2 as well as of 2, 12 and 4 expected from gravitational separation. These statistically significant differences clearly show that the effect of thermal diffusion on our observation data is negligibly small. Previous studies have reported thermal diffusion factors' ratios of approximately 1.6 (Grew and Ibbs, 1952; Severinghaus et al.,
2001 ) and 2.6 (Severinghaus et al., 2001) for $\delta\left({ }^{18} \mathrm{O}\right) / \delta\left({ }^{15} \mathrm{~N}\right)$ and $\delta\left({ }^{40} \mathrm{Ar}\right) / \delta\left({ }^{15} \mathrm{~N}\right)$, respectively, which are consistent with our experimental results. Therefore, we conclude that gravitational separation of the major atmospheric components is clearly observable, not only above the turbopause but also in the stratosphere.

\subsection{Effect of gravitational separation on the $\delta\left(\mathrm{O}_{2} / \mathrm{N}_{2}\right)$ and $\mathrm{CO}_{2}$ mole fraction in the stratosphere}

In order to determine the magnitude of gravitational separation in the stratosphere, we define a parameter " $<\delta>$ " as an average value of $\delta\left({ }^{15} \mathrm{~N}\right)$ of $\mathrm{N}_{2}, \delta\left({ }^{18} \mathrm{O}\right) / 2$ of $\mathrm{O}_{2}, \delta\left(\mathrm{Ar} / \mathrm{N}_{2}\right) / 12$ and $\delta\left({ }^{40} \mathrm{Ar}\right) / 4$ for each collected air sample. From its vertical profile, we are able to evaluate the effects of the gravitational separation on the mole fraction ( $\left.\Delta X_{\text {grav }}\right)$ and the isotopic ratio $\left(\Delta \delta_{\text {grav }}\right)$ of a specified atmospheric component at a certain altitude using the following equations:

$\Delta X_{\mathrm{grav}} \approx X \times\left(m-m_{\mathrm{air}}\right) \times \Delta<\delta>$

and

$\Delta \delta_{\text {grav }}=\Delta m \times \Delta<\delta>$.

Here, $X$ is the mole fraction of the specified component, $m$ and $m_{\text {air }}$ denote the relative molecular masses of the specified component and air, respectively, and $\Delta<\delta>$ is the difference in the measured $\langle\delta\rangle$ value from its tropospheric value. Equations (3) and (4) are similar to Eq. (3) in Etheridge et al. (1996) and Eq. (10) in Severinghaus and Battle (2006), respectively, which were used to evaluate gravitational separation of atmospheric components in polar firn.

It is expected from the above discussion that the tropospheric air having intruded into the tropical stratosphere is affected by gravitational separation during poleward transport. To exclude this effect, the data of $\delta\left(\mathrm{O}_{2} / \mathrm{N}_{2}\right)$ and $\mathrm{CO}_{2}$ mole fraction $\left(\mu \mathrm{mol} \mathrm{mol}^{-1}\right)$ taken at altitudes above $18-25 \mathrm{~km}$ since 1999 were corrected for gravitational separation using Eqs. (4) and (3), respectively, and their averages for each year are shown in Fig. 3. As seen in the figure, the corrected values of $\delta\left(\mathrm{O}_{2} / \mathrm{N}_{2}\right)$ are significantly higher than the observed values. In addition, variability in the $\delta\left(\mathrm{O}_{2} / \mathrm{N}_{2}\right)$ value, represented by the error bars in Fig. 3, is much reduced by applying the gravitational separation correction. On the other hand, the difference between the $\mathrm{CO}_{2}$ mole fraction with and without the correction is quite small $\left(0.14-0.36 \mu \mathrm{mol} \mathrm{mol}^{-1}\right)$. These results imply that the gravitational separation correction is necessary when extremely small variations of abundant atmospheric components are discussed.

It is also obvious in Fig. 3 that the stratospheric $\delta\left(\mathrm{O}_{2} / \mathrm{N}_{2}\right)$ value, corrected for the gravitational separation, decreases secularly following a similar temporal change in the upper troposphere over Japan, mainly due to anthropogenic fossil fuel combustion (Ishidoya et al., 2012). By comparing the stratospheric $\mathrm{CO}_{2}$ and $\mathrm{SF}_{6}$ mole fraction with their mole 


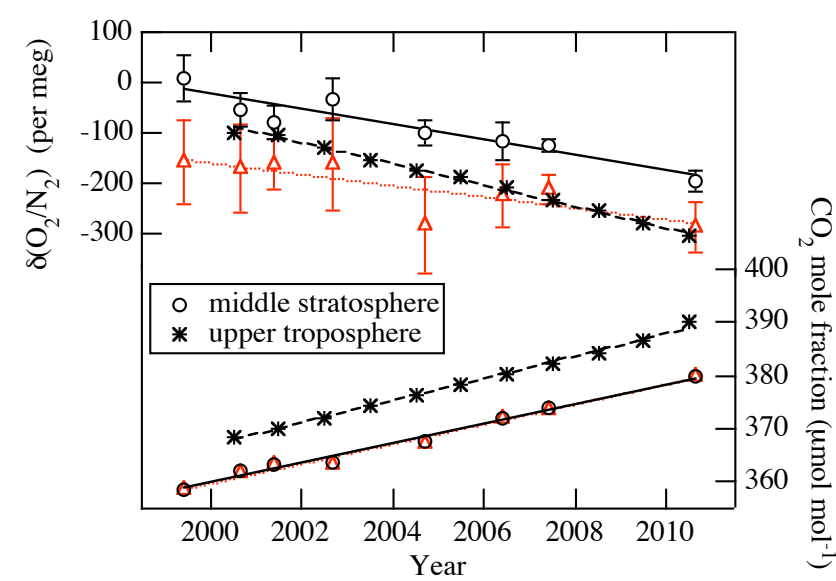

Fig. 3. Average values of $\delta\left(\mathrm{O}_{2} / \mathrm{N}_{2}\right)$ and the $\mathrm{CO}_{2}$ mole fraction observed above $18-25 \mathrm{~km}$ over Sanriku and Taiki, Japan, for the period 1999-2010, after (black open circles) and before (red triangles) correcting for the gravitational separation effect. Asterisks denote the annual mean values of $\delta\left(\mathrm{O}_{2} / \mathrm{N}_{2}\right)$ and the $\mathrm{CO}_{2}$ mole fraction observed in the upper troposphere over Japan for the period 2000-2010.

fraction histories in the equatorial troposphere, the middle stratospheric air is found to be older by several years than the tropospheric air (e.g., Waugh and Hall, 2002). If the gravitational separation effect is reasonably corrected by the above method, then the obtained stratospheric $\delta\left(\mathrm{O}_{2} / \mathrm{N}_{2}\right)$ values should yield a mean age similar to that derived from the $\mathrm{CO}_{2}$ mole fraction data. In this study, the data of equatorial tropospheric $\delta\left(\mathrm{O}_{2} / \mathrm{N}_{2}\right)$ are not available. Therefore, we simply calculated average time lags between the corrected middle stratospheric and upper tropospheric values of $\delta\left(\mathrm{O}_{2} / \mathrm{N}_{2}\right)$ and $\mathrm{CO}_{2}$ mole fraction shown in Fig. 3 by shifting the relevant solid line to match the corresponding dashed line. The average time lag, thus obtained, is $(3.9 \pm 0.9)$ years for $\delta\left(\mathrm{O}_{2} / \mathrm{N}_{2}\right)$ and $(4.0 \pm 0.4)$ years for the $\mathrm{CO}_{2}$ mole fraction, both values being consistent with each other. This agreement strongly suggests that the present gravitational separation correction is appropriate. The time lags obtained by this method are shorter by about $1 \mathrm{yr}$ than our " $\mathrm{CO}_{2}$ age" to be appeared in Figs. 5 and 6, which was calculated from the middle stratospheric and equatorial tropospheric $\mathrm{CO}_{2}$ mole fractions, reflecting different tropospheric $\mathrm{CO}_{2}$ mole fractions between the tropics and northern mid-latitudes. It is noted that the $<\delta>$ and the $\mathrm{CO}_{2}$ age measured over Sanriku in 1995, 1999, 2000, 2001, 2002, 2004, 2006 and 2007, as well as over Taiki in 2010, are also given in the Supplement Tables S2-S10, respectively.

\subsection{Numerical simulation of gravitational separation}

Existence of gravitational separation in the stratosphere was also confirmed theoretically by numerical model simulations. As a first attempt, a 2-dimensional model of the middle at- mosphere (SOCRATES) developed by National Center for Atmospheric Research (NCAR) was used to evaluate the basic structure of gravitational separation in the stratosphere. In this model, mass transport processes caused by molecular diffusion were originally taken into account only above the mesosphere, since the molecular diffusion effect was thought to be negligibly small in the stratosphere compared with the eddy diffusion effect. In this study, we simply lowered its vertical domain to the tropopause for the calculation of molecular diffusion. Molecular diffusion theory included in SOCRATES is based on Banks and Kockarts (1973),

$f_{i}=-D_{i}\left[\frac{\partial C_{i}}{\partial z}+\frac{C_{i}}{H_{i}}+\left(1+\alpha_{\mathrm{T} i}\right) \frac{C_{i}}{T} \frac{\partial T}{\partial z}\right]$,

where $f_{i}, D_{i}, C_{i}, H_{i}$ and $\alpha_{\mathrm{T} i}$ are the vertical flux by molecular diffusion, the molecular diffusion coefficient, the number density, the scale height and the thermal diffusion factor for species $i$, respectively. We assumed $\alpha_{T i}$ to be zero, since the thermal diffusion effect would be of no importance in the stratosphere. The lesser importance of the thermal diffusion than gravitational separation was confirmed below $40 \mathrm{~km}$ by a simulation assuming the $\alpha_{T i}$ to be 0.01 , which is a rough approximation of the $\alpha_{\mathrm{T} i}$ for the mixtures of ${ }^{15} \mathrm{~N}^{14} \mathrm{~N}-{ }^{14} \mathrm{~N}_{2}$ (or ${ }^{18} \mathrm{O}^{16} \mathrm{O}-{ }^{16} \mathrm{O}^{16} \mathrm{O},{ }^{40} \mathrm{Ar}-{ }^{36} \mathrm{Ar}$ ) at $255 \mathrm{~K}$ (Severinghaus et al., 2001). The molecular diffusion coefficient is given by

$$
\begin{aligned}
& D_{i} /\left(\mathrm{cm}^{2} \mathrm{~s}^{-1}\right)=1.52 \times 10^{18}\left(\mathrm{~cm}^{-1} \mathrm{~s}^{-1} \mathrm{~kg}^{-1 / 2} \mathrm{~K}^{-1 / 2}\right) \\
& \times\left(\frac{1}{m_{\text {air }}}+\frac{1}{m_{i}}\right)^{1 / 2} \frac{\sqrt{T}}{N},
\end{aligned}
$$

where $m_{\text {air }}$ has the same meaning as above, and $m_{i}$ and $N$ are the mean relative molecular mass of species $i$ and the number density of air, respectively. Based on this model setup, we calculated height-latitude distributions of ${ }^{12} \mathrm{C}^{16} \mathrm{O}_{2}\left(m_{i}=44\right)$ and ${ }^{13} \mathrm{C}^{16} \mathrm{O}_{2}\left(m_{i}=45\right)$ mole fractions, and then derived the isotopic ratio,

$$
\delta\left({ }^{13} \mathrm{C}^{16} \mathrm{O}_{2}\right)=\frac{\left[n\left({ }^{13} \mathrm{C}^{16} \mathrm{O}_{2}\right) / n\left({ }^{12} \mathrm{C}^{16} \mathrm{O}_{2}\right)\right]_{\text {strat }}}{\left[n\left({ }^{13} \mathrm{C}^{16} \mathrm{O}_{2}\right) / n\left({ }^{12} \mathrm{C}^{16} \mathrm{O}_{2}\right)\right]_{\text {trop }}}-1 .
$$

Here, subscripts "trop" and "strat" denote the tropospheric and stratospheric values, respectively. In this study, we used the isotopic ratios of $\mathrm{CO}_{2}$ to simulate the $\langle\delta>$ value instead of those of $\mathrm{N}_{2}, \mathrm{O}_{2}$ and $\mathrm{Ar}$ obtained from our measurements, since most chemistry-climate models including SOCRATES cannot calculate the mole fractions and isotopic ratios of major components of the atmosphere. However, as seen from Eq. (4), the effect of gravitational separation on the isotopic ratio depends not on the atmospheric component but on $\Delta m$. We also confirmed, using SOCRATES, that variations in the simulated vertical profile of $\delta\left({ }^{12} \mathrm{C}^{18} \mathrm{O}^{16} \mathrm{O}\right.$ $\left.\left(m_{i}=46\right)\right)(\Delta m=2)$ are just twice larger than those of $\delta\left({ }^{13} \mathrm{C}^{16} \mathrm{O}_{2}\right)(\Delta m=1)$. Therefore, gravitational separation of major stratospheric components can be discussed using the $<\delta>$ value simulated for $\delta\left({ }^{13} \mathrm{C}^{16} \mathrm{O}_{2}\right)$. 

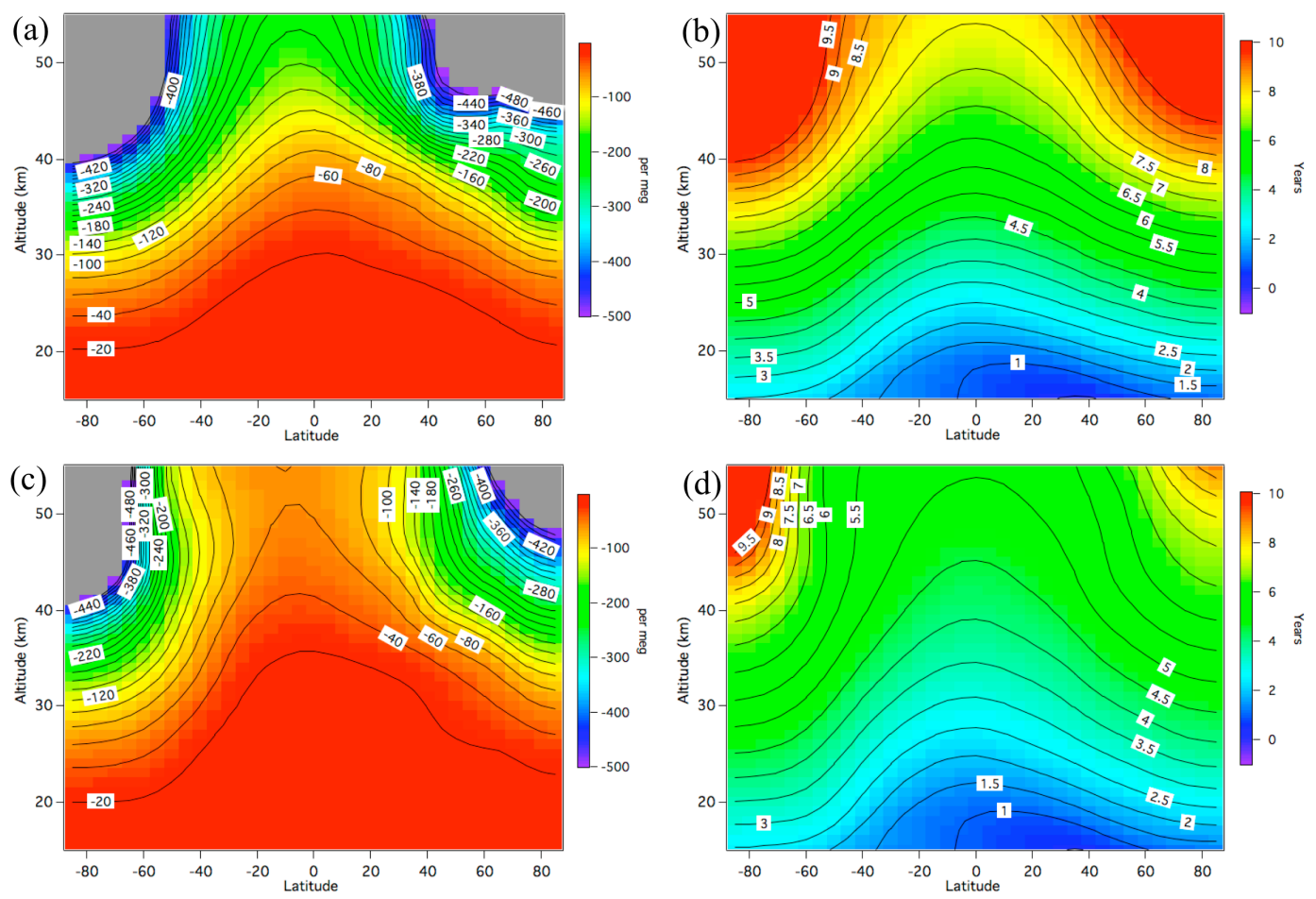

Fig. 4. Annual mean height-latitude distributions of (a) $<\delta>$ value (per meg) and (b) $\mathrm{CO}_{2}$ age (years) calculated using the SOCRATES model for Control Run, and the corresponding results for Enhanced BDC (c and d). The $\delta$ values lower than -500 per meg are shown by gray shades.

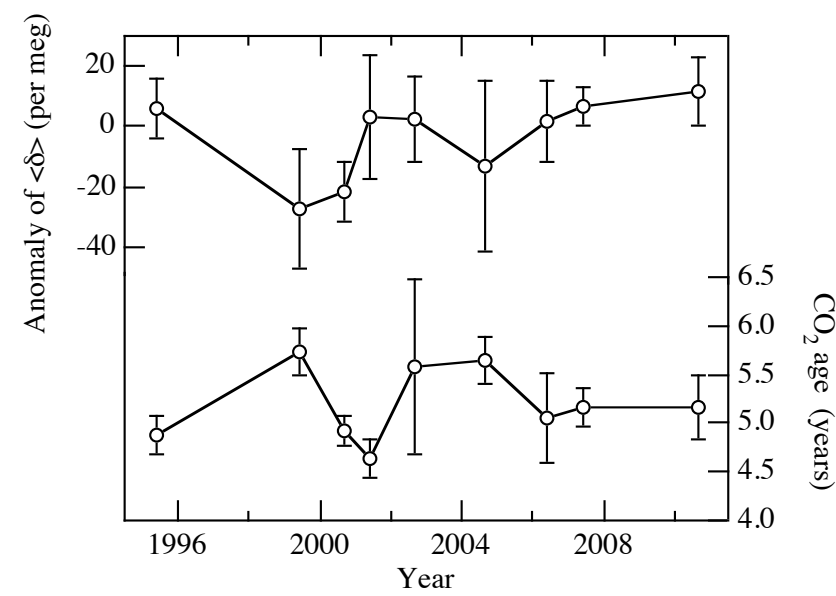

Fig. 5. Average values of the deviations of $\langle\delta>$ from its mean vertical profile over the observation period (upper) and those of the $\mathrm{CO}_{2}$ ages (lower) at heights above $20-28 \mathrm{~km}$ for the respective years.

In the actual atmosphere, the ${ }^{13} \mathrm{C}^{16} \mathrm{O}_{2} /{ }^{12} \mathrm{C}^{16} \mathrm{O}_{2}$ ratio has been decreasing secularly due to the emissions of isotopically light $\mathrm{CO}_{2}$ by human activities. However, in this study, we assumed the ${ }^{13} \mathrm{C}^{16} \mathrm{O}_{2} /{ }^{12} \mathrm{C}^{16} \mathrm{O}_{2}$ ratio to be constant in the lowermost layer of the model, since our aim is to simulate the gravitational separation on ${ }^{12} \mathrm{C}^{16} \mathrm{O}_{2}$ and ${ }^{13} \mathrm{C}^{16} \mathrm{O}_{2}$ molecules. The boundary conditions and other input data for the present simulations were the same as for the SOCRATES baseline-atmosphere run (Huang et al., 1998). At first, a $20 \mathrm{yr}$ spin-up calculation was carried out with no $\mathrm{CO}_{2}$ increase in the troposphere, and then a $30 \mathrm{yr}$ simulation was performed with monotonically increasing $\mathrm{CO}_{2}$ at the model surface, to evaluate both the $\mathrm{CO}_{2}$ age and gravitational separation on ${ }^{12} \mathrm{C}^{16} \mathrm{O}_{2}$ and ${ }^{13} \mathrm{C}^{16} \mathrm{O}_{2}$. The $\mathrm{CO}_{2}$ age was simply defined as a time difference between the appearance of the same $\mathrm{CO}_{2}$ mole fraction in the stratosphere and the troposphere. Since the $\mathrm{CO}_{2}$ age obtained from the model simulation was obviously underestimated compared with the observational result, probably due to atmospheric circulation moving too fast, the meridional mass transport was arbitrarily suppressed by changing the meridional mass stream function in this study so that the model-calculated $\mathrm{CO}_{2}$ ages at northern midlatitudes were close to the results observed over Japan. The results obtained under this condition are referred to as "Control Run".

Regarding the $\mathrm{CO}_{2}$ age underestimated by SOCRATES, it is interesting to describe the study of Park et al. (1999), in which the global mean ages of the stratospheric air derived using various models, including SOCRATES, are examined in detail. They found that almost all models show lower mean ages for the lower and middle stratosphere compared to observations. They also suggested that the mean age 

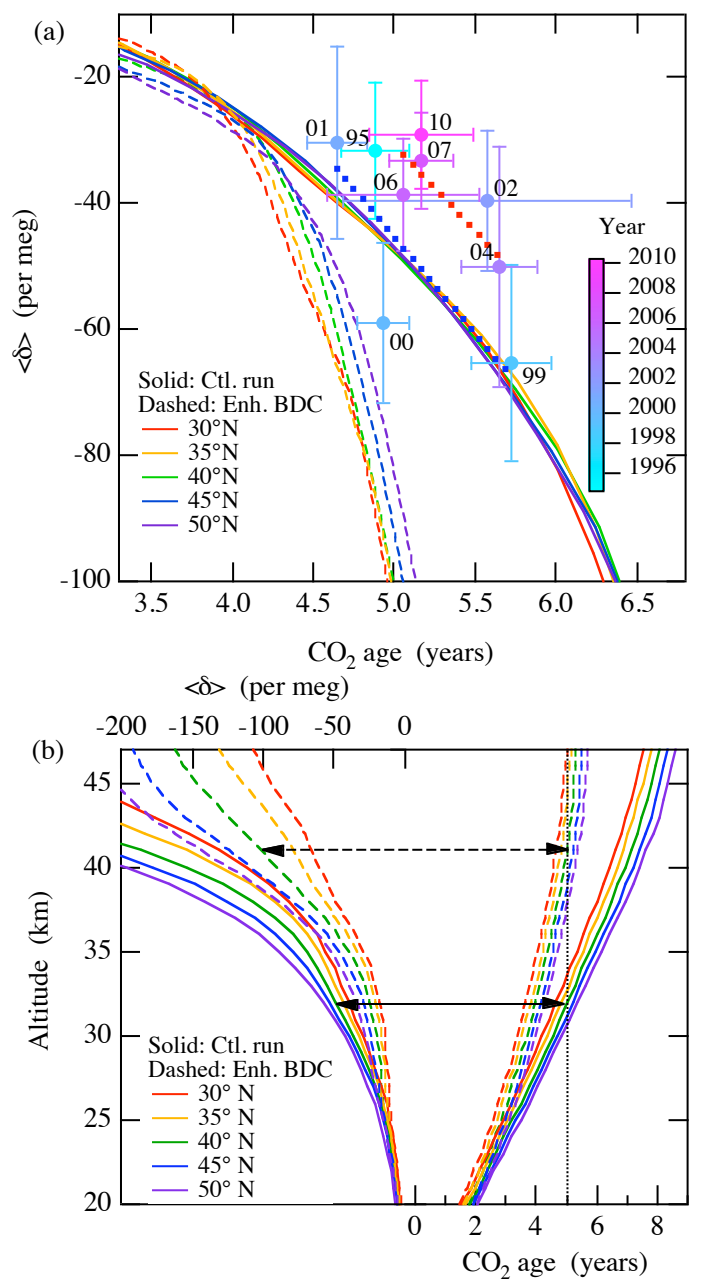

Fig. 6. (a) Plots of the $<\delta>$ value at $29 \mathrm{~km}$ against the average values of $\mathrm{CO}_{2}$ ages at heights above $20-28 \mathrm{~km}$ for the respective observations over Sanriku and Taiki, Japan (closed circles). Color bar and Arabic numerals near the symbols indicate the observation years. The results calculated using the SOCRATES model for Control Run (solid lines) and Enhanced BDC (dashed lines) are also shown. Blue and red dotted lines represent the results obtained by applying a linear regression analysis to the data for the periods 1995-2001 and 2004-2010, respectively. It is noted that the result for 2002 is not used in the regression analysis, since the error in the $\mathrm{CO}_{2}$ age estimated for that year is significantly larger compared to the other years due to large variability in the vertical $\mathrm{CO}_{2}$ profile observed in that year. It is also noted that the observed $<\delta>$ values at $29 \mathrm{~km}$, which is approximately the highest altitude covered by all our observations, are the values obtained by applying linear least squares fits to the vertical $\langle\delta>$ profiles for the respective years, and their error bars denote standard deviations $( \pm 1 \sigma)$ of the $\langle\delta>$ values from the respective fitted lines. On the other hand, since the vertical gradients of the $\mathrm{CO}_{2}$ age are not significant above $20-28 \mathrm{~km}$, we use the average values of $\mathrm{CO}_{2}$ ages above these altitudes. (b) Vertical profiles of the $<\delta>$ values and the $\mathrm{CO}_{2}$ ages calculated using the SOCRATES model for Control Run (solid lines) and Enhanced BDC (dashed lines). Black solid (dashed) line denotes the $\langle\delta>$ values for the $\mathrm{CO}_{2}$ age of $5 \mathrm{yr}$ at $40^{\circ} \mathrm{N}$ for Control Run (Enhanced BDC). should be increased by reducing the residual circulation magnitude and/or by enhancing the mixing of extratropical and tropical air. In this connection, the latter may partly explain the age underestimation by models, since the $\mathrm{CO}_{2}$ ages estimated from our balloon observations are consistent with those reported by Ray et al. (2010) using a Tropical Leaky Pipe (TLP) model with fast horizontal mixing in the lower stratosphere.

The annual mean distributions of the $<\delta>$ value and the $\mathrm{CO}_{2}$ age calculated using SOCRATES are shown in Fig. $4 \mathrm{a}$ and $\mathrm{b}$, respectively. The height-latitude distribution of the $\mathrm{CO}_{2}$ age is close to those summarized by Waugh and Hall (2002) on the basis of the observations and model simulations. Simulated vertical distributions of the $\langle\delta\rangle$ value and the $\mathrm{CO}_{2}$ age at northern mid-latitudes are almost consistent with the observational results. The model result predicts that the vertical gradient of the $\langle\delta\rangle$ value increases with increasing height especially at mid- and high latitudes and that the differences between low and high latitudes will be also observable. The basic structure of the verticalmeridional distribution of the $\langle\delta\rangle$ value reproduced by model calculations can be interpreted as a result of a balance between the mass-dependent molecular diffusions and the mass-independent transport processes in the stratosphere.

\subsection{Gravitational separation as a new indicator of atmospheric circulation}

Our observational results show that the $\langle\delta>$ value always decreases with increasing altitude due to the gravitational separation effect, but the vertical gradient is different depending on observation. To examine the temporal variations of the vertical gradient, we calculated an average vertical profile of $<\delta>$ by applying a linear least squares fit to all the profiles observed in this study and then obtained deviations of the respective $<\delta>$ values from the average profile. The average of the deviation values of $<\delta>$ above $20-28 \mathrm{~km}$ for each observation is shown in Fig. 5 as $<\delta>$ anomaly, together with the $\mathrm{CO}_{2}$ age calculated from our stratospheric and equatorial tropospheric mole fraction data (Nakazawa et al., 1997). The results indicate that the $\langle\delta>$ anomaly is negatively correlated with the $\mathrm{CO}_{2}$ age, which means that gravitational separation becomes stronger when the relevant stratospheric air becomes older.

As described in the previous section, the magnitude of gravitational separation at a certain altitude in the stratosphere is basically determined by the molecular diffusion and the mass-independent atmospheric transport. Therefore, the $\mathrm{CO}_{2}$ age and the $<\delta>$ value would be affected to some extent by changes in the stratospheric circulation, such as an enhanced BDC due to global warming. To examine how the $\mathrm{CO}_{2}$ age and the $<\delta>$ value are influenced by changes in the stratospheric circulation, model simulations were further made by arbitrarily changing the meridional mass stream function so that the $\mathrm{CO}_{2}$ age decreased to about $80 \%$ at 
$30 \mathrm{~km}$ over northern mid-latitudes, in accordance with the prediction made by a past study (Austin and $\mathrm{Li}, 2006$ ) for potential global warming effects over the period 1960-2100, in which the BDC is accelerated due to global warming. The results obtained under this condition are referred to as "Enhanced BDC". The annual mean distributions of the $<\delta>$ value and the $\mathrm{CO}_{2}$ age calculated using SOCRATES for Enhanced BDC are shown in Fig. $4 \mathrm{c}$ and d, respectively. The annual mean relationships between the $\mathrm{CO}_{2}$ age and the $<\delta>$ value obtained from the Control Run and Enhanced BDC simulations for northern mid-latitudes are also shown in Fig. 6a, together with the observational results over Japan.

As seen in Fig. 6a, the relationships between the $\mathrm{CO}_{2}$ age and the $\langle\delta\rangle$ value for Control Run at northern mid-latitudes are fairly close to the observational results over Japan, which implies that both the $\mathrm{CO}_{2}$ age and the $<\delta>$ value can be almost reproduced by SOCRATES. However, the relationships for Enhanced BDC are clearly different from those of Control Run, indicating that the $\mathrm{CO}_{2}$ age and the $<\delta>$ value respond differently to changes in the stratospheric transport, i.e., gravitational separation for the air molecules with the same age is enhanced when the BDC is accelerated. To see such a behavior in more detail, vertical profiles of the two variables for Control Run are compared in Fig. $6 \mathrm{~b}$ with those for Enhanced BDC. It is clearly seen from this figure that gravitational separation is weakened and the $\mathrm{CO}_{2}$ age is decreased by enhancing the BDC. It is also found that the $<\delta>$ value of about -50 per meg and the $\mathrm{CO}_{2}$ age of 5.0 years are found at $31-34 \mathrm{~km}$ over the northern mid-latitudes for Control Run, while Enhanced BDC shows about -100 per meg for the $\left\langle\delta>\right.$ value and $5.0 \mathrm{yr}$ for the $\mathrm{CO}_{2}$ age at $38-47 \mathrm{~km}$ over the same latitude region. This phenomenon is caused by a strong height dependency of gravitational separation due to the fact that the molecular diffusion coefficient increases with increasing height.

It is not easy to detect a long-term change in the BDC only from the $\mathrm{CO}_{2}$ age derived from spatiotemporally discrete balloon observations because of its year-by-year variability superimposed on a secular trend. On the other hand, the results given in Fig. 6 indicate that not only the $\mathrm{CO}_{2}$ age but also the $\langle\delta>$ value, as well as their relationship, are clearly changed when the BDC varies. As seen from Fig. 5, the observed year-by-year variability of the $\langle\delta\rangle$ value is inversely correlated with that of the $\mathrm{CO}_{2}$ age. This suggests that the influence of year-by-year variability is reduced by inspecting the two variables simultaneously and that a long-term change in the BDC can be detected as a change in the correlation between age and gravitational separation. Therefore, simultaneous observation of the $<\delta>$ value and the $\mathrm{CO}_{2}$ age would provide more reliable information about a long-term change in the BDC than that of only the $\mathrm{CO}_{2}$ age. It is actually found from our observational results shown in Fig. 6a that gravitational separation for the air with the same age slightly weakened with time for the period 1995-2010. This tendency is just the opposite of that expected from the En- hanced BDC simulation. Balloon and satellite observations (Engel et al., 2009; Stiller et al., 2012) reported that the $\mathrm{CO}_{2}$ and $\mathrm{SF}_{6}$ ages in the stratosphere over northern mid-latitudes showed no significant trend over the last $30 \mathrm{yr}$, while the satellite measurements indicate that the $\mathrm{SF}_{6}$ age might have increased for the period 2002-2010. Our long-term record of the middle stratospheric $\mathrm{CO}_{2}$ mole fraction over Japan for the period 1985-2010 also shows a slight secular increase in the $\mathrm{CO}_{2}$ age (our unpublished data, but the $\mathrm{CO}_{2}$ age values for a limited time period of 1986-2001 are available from Engel et al., 2009). These observational results on gravitational separation and the air age could imply that the BDC has not changed significantly or weakened slightly over the past 10-30 yr, in conflict with the model prediction of an enhancement of the BDC due to global warming (Austin and Li, 2006; Li et al., 2008).

With respect to this interpretation, it may be worthwhile to describe the results of simulations made by Ray et al. (2010) using the TLP model. Ray et al. (2010) reported that a weakening of the mean circulation in the middle and upper stratosphere is of importance for obtaining an agreement with the observed mean age over the past 3 decades. Their finding would strongly support the above-mentioned observational results. However, they also pointed out that the mean age trend is sensitive to the horizontal mixing into the tropics. Therefore, it is further necessary to examine how the horizontal mixing affects not only the mean age but also gravitational separation using stratospheric transport models.

\section{Conclusions}

To detect gravitational separation in the stratosphere, the stratospheric air samples collected over Japan were analyzed for $\delta\left({ }^{15} \mathrm{~N}\right)$ of $\mathrm{N}_{2}, \delta\left({ }^{18} \mathrm{O}\right)$ of $\mathrm{O}_{2}, \delta\left(\mathrm{O}_{2} / \mathrm{N}_{2}\right), \delta\left(\mathrm{Ar} / \mathrm{N}_{2}\right)$ and $\delta\left({ }^{40} \mathrm{Ar}\right)$. The vertical profiles of $\delta\left({ }^{18} \mathrm{O}\right) / 2, \delta\left(\mathrm{Ar} / \mathrm{N}_{2}\right) / 12$, $\delta\left({ }^{40} \mathrm{Ar}\right) / 4$ and $\delta\left({ }^{15} \mathrm{~N}\right)$ of $\mathrm{N}_{2}$ showed a gradual decrease with height, their average difference between the lowermost part of the stratosphere and $32 \mathrm{~km}$ being about 45 per meg. The relationships of $\delta\left({ }^{18} \mathrm{O}\right), \delta\left(\mathrm{Ar} / \mathrm{N}_{2}\right)$ and $\delta\left({ }^{40} \mathrm{Ar}\right)$ with $\delta\left({ }^{15} \mathrm{~N}\right)$ of $\mathrm{N}_{2}$ were $(2.1 \pm 0.2),(11.9 \pm 1.4)$ and $(4.2 \pm 0.6)$ per meg per $\mathrm{meg}^{-1}$, respectively. These ratios are consistent with the corresponding values of 2,12 and 4 per meg per meg ${ }^{-1}$ expected from gravitational separation, but are clearly different from $(1.55 \pm 0.02),(16.2 \pm 0.1)$ and $(2.75 \pm 0.05)$ per meg per $\mathrm{meg}^{-1}$ determined experimentally for a possible thermal diffusion effect at the air intake of the cryogenic air sampler. This fact indicates that gravitational separation of the major atmospheric components is clearly observable even in the stratosphere.

By using a parameter " $<\delta>$ " defined as an average of $\delta\left({ }^{15} \mathrm{~N}\right)$ of $\mathrm{N}_{2}, \delta\left({ }^{18} \mathrm{O}\right) / 2$ of $\mathrm{O}_{2}, \delta\left(\mathrm{Ar} / \mathrm{N}_{2}\right) / 12$ and $\delta\left({ }^{40} \mathrm{Ar}\right) / 4$ for each collected air sample, we corrected the values of $\delta\left(\mathrm{O}_{2} / \mathrm{N}_{2}\right)$ observed in the middle stratosphere for gravitational separation. The $\delta\left(\mathrm{O}_{2} / \mathrm{N}_{2}\right)$ values, thus corrected, were 
found to be significantly higher than the observed values. This implies that gravitational separation correction is necessary when extremely small variations of abundant atmospheric components are discussed. It was also found that the corrected values of $\delta\left(\mathrm{O}_{2} / \mathrm{N}_{2}\right)$ show a secular decrease similar to temporal change in the troposphere, and that the mean age of the middle stratospheric air calculated from $\delta\left(\mathrm{O}_{2} / \mathrm{N}_{2}\right)$ is consistent with the $\mathrm{CO}_{2}$ age.

To examine how the $\mathrm{CO}_{2}$ age and the $<\delta>$ value are influenced by changes in the stratospheric circulation, we made numerical simulations using the SOCRATES model. It was found from the simulations that the $\mathrm{CO}_{2}$ age and the $\langle\delta>$ value respond differently to changes in the stratospheric transport. The simulation results also indicate that the gravitational separation for the air with the same age is strengthened if the BDC is enhanced due to global warming, which is just the opposite of our observational result for the period 1995-2010.

The $\langle\delta>$ value is a new, unique and excellent indicator to represent how much the gravitational separation occurs in the stratosphere. Therefore, analyses of the $\langle\delta\rangle$ value, in addition to the $\mathrm{CO}_{2}$ and $\mathrm{SF}_{6}$ ages, would provide us with useful information about the stratospheric circulation. However, observations of gravitational separation are still sparse. By taking longer records of the $\langle\delta\rangle$ value, we can detect a change in the BDC due to global warming, a feat that has not been achieved so far. Knowledge obtained from observations of gravitational separation also contributes to further progression of atmospheric science, especially for the middle atmosphere.

\section{Supplementary material related to this article is available online at: http://www.atmos-chem-phys.net/13/ 8787/2013/acp-13-8787-2013-supplement.pdf.}

Acknowledgements. We deeply thank the balloon engineering group of the Institute of Space and Astronautical Science JAXA for their cooperation in our stratospheric air sampling. This work is partly supported by the Grants-in-Aid for Creative Scientific Research (2005/17GS0203), the Grants-in-Aid for Scientific Research (2006/18710004) and the subsidized project "Formation of a virtual laboratory for diagnosing the earth's climate system" of the Ministry of Education, Science, Sports and Culture, Japan.

Edited by: J. Kaiser

\section{References}

Adachi, Y., Kawamura, K., Armi, L., and Keeling, R. F.: Diffusive separation of the lower atmosphere, Science, 311, 1429, 2006.

Aoki, S., Nakazawa, T., Machida, T., Sugawara, S., Morimoto, S., Hashida, G., Yamanouchi, T., Kawamura, K., and Honda, H.: Carbon dioxide variations in the stratosphere over Japan, Scandinavia and Antarctica, Tellus, 55B, 178-186, 2003.
Austin, J. and Li, F.: On the relationship between the strength of the Brewer-Dobson circulation and the age of stratospheric air, Geophys. Res. Lett., 33, L17807, doi:10.1029/2006GL026867, 2006.

Banks, P. M. and Kockarts, G.: Aeronomy, Parts A and B, Academic Press, Inc. New York, USA, 32-63, 1973.

Bender, M. L., Tans, P. P., Ellis, J. T., Orchard, J., and Habfast, K.: High precision isotope ratio mass spectrometry method for measuring the $\mathrm{O}_{2} / \mathrm{N}_{2}$ ratio of air, Geochim. Cosmochim. Acta, 58, 4751-4758, 1994.

Blaine, T. W., Keeling, R. F., and Paplawsky, W. J.: An improved inlet for precisely measuring the atmospheric $\mathrm{Ar} / \mathrm{N}_{2}$ ratio, Atmos. Chem. Phys., 6, 1181-1184, doi:10.5194/acp-6-1181-2006, 2006.

Brewer, A.: Evidence for a world circulation provided by the measurement of helium and water vapor in the stratosphere, Q. J. Roy. Meteorol. Soc., 75, 351-363, 1949.

Engel, A., Möbius, T., Bönisch, H., Schmidt, U., Heinz, R., Levin, I., Atlas, E., Aoki, S., Nakazawa, T., Sugawara, S., Moore, F., Hurst, D., Elkins, J., Schauffler, S., Andrews, A., and Boering, K.: Age of stratospheric air unchanged within uncertainties over the past 30 years, Nature Geosci., 2, 28-31, doi:10.1038/Ngeo388, 2009.

Etheridge, D. M., Steele, L. P., Langenfelds, R. L., Francey, R. J., Barnola, J.-M., and Morgan, V. I.: Natural and anthropogenic changes in atmospheric $\mathrm{CO}_{2}$ over the last 1000 years from air in Antarctic ice and firn, J. Geophys. Res., 101, 4115-4128, 1996.

Grew, K. E. and Ibbs, L. T.: Thermal Diffusion in Gases, Cambridge Univ. Press, New York, USA, 151 pp., 1952.

Honda, H.: Balloon-borne cryogenic whole air sampling system, ISAS Research Note 433, The Institute of Space and Astronautical Science, Sagamihara, Japan, 1990.

Honda, H., Aoki, S., Nakazawa, T., Morimoto, S., and Yajima, N.: Cryogenic air sampling system for measurements of the concentrations of stratospheric trace gases and their isotopic ratios over Antarctica, J. Geomagn. Geoelectr., 48, 1145-1155, 1996.

Huang, T. Walters, S., Brasseur, G., Hauglustaine, D., and Wu, W.: Description of SOCRATES - A chemical dynamical radiative two-dimensional model, NCAR/TN-440+EDD NCAR TECHNICAL NOTE, 1998.

Ishidoya, S., Aoki, S., and Nakazawa, T.: High precision measurements of the atmospheric $\mathrm{O}_{2} / \mathrm{N}_{2}$ ratio on a mass spectrometer, J. Meteorol. Soc. Japan, 81, 127-140, 2003.

Ishidoya, S., Sugawara, S., Hashida, G., Morimoto, S., Aoki, S., Nakazawa, T., and Yamanouchi, T.: Vertical profiles of the $\mathrm{O}_{2} / \mathrm{N}_{2}$ ratio in the stratosphere over Japan and Antarctica, Geophys. Res. Lett., 33, L13701, doi:10.1029/2006GL025886, 2006.

Ishidoya, S., Sugawara, S., Morimoto, S., Aoki, S., and Nakazawa, T.: Gravitational separation of major atmospheric components of nitrogen and oxygen in the stratosphere, Geophys. Res. Lett., 35, L03811, doi:10.1029/2007GL030456, 2008a.

Ishidoya, S., Morimoto, S., Sugawara, S., Watai, T., Machida, T. Aoki, S., Nakazawa, T., and Yamanouchi, T.: Gravitational separation suggested by $\mathrm{O}_{2} / \mathrm{N}_{2}, \delta^{15} \mathrm{~N}$ of $\mathrm{N}_{2}, \delta^{18} \mathrm{O}$ of $\mathrm{O}_{2}, \mathrm{Ar} / \mathrm{N}_{2}$ observed in the lowermost part of the stratosphere at northern middle and high latitudes in the early spring of 2002, Geophys. Res. Lett., 35, L03812, doi:10.1029/2007GL031526, 2008b.

Ishidoya, S., Aoki, S. Goto, D., Nakazawa, T., Taguchi, S., and Patra, P. K.: Time and space variations of the $\mathrm{O}_{2} / \mathrm{N}_{2}$ ratio in the tro- 
posphere over Japan and estimation of global $\mathrm{CO}_{2}$ budget, Tellus B, 64, 18964, 10.3402/tellusb.v64i0.18964, 2012.

Jacob, D. J.: Introduction to Atmospheric Chemistry, Princeton University Press, Princeton, 267 pp., 1999.

Khosravi, R., Brasseur, G., Smith, A., Rusch, D., Walters, S., Chabrillat, and Kockarts, G.: Response of the mesosphere to human-induced perturbations and solar variability calculated by a 2-D model, J. Geophys. Res., 107, 4358, doi:10.1029/2001JD001235, 2002.

Lettau, H.: Diffusion in the upper atmosphere, Compendium of Meteorology, American Meteorological Society, Boston, 1951.

Lewis, J. S. and Prinn R. G.: Planets and Their Atmosphere: origin and evolution, International Geophysics Series, 33, Academic Press Inc., 33, 470 pp., 1984.

Li, F., Austin, J., and Wilson, J.: The Strength of the Brewer-Dobson Circulation in a changing climate: Coupled chemistry-climate model simulations, J. Climate, 21, 40-57, doi:10.1175/2007JCLI1663.1, 2008.

Massie, S. T. and Hunten, D. M.: Stratospheric eddy diffusion coefficients from tracer data, J. Geophys. Res., 86, 9859-9868, 1981.

Nakazawa, T., Machida, T., Sugawara, S., Murayama, S., Morimoto, S., Hashida, G., Honda, H., and Itoh, T.: Measurements of the stratospheric carbon dioxide concentration over Japan using a Balloon-borne cryogenic sampler, Geophys. Res. Lett., 22, p. 1229, doi:10.1029/95GL01188, 1995.

Nakazawa, T., Morimoto, S., Aoki, S., and Tanaka, M.: Temporal and spatial variations of the carbon isotopic ratio of atmospheric carbon dioxide in the western Pacific region, J. Geophys. Res., 102, 1271-1285, 1997.
Park, J. H., Ko, M. K. W., Jackman, C. H., Plumb, R. A., Kaye, J. A., Sage, K. H.: Models and Measurements Intercomparison II, NASA/TM-1999-209554, http://www.cs.odu.edu/ mln/ ltrs-pdfs/NASA-99-tm209554.pdf, 1999.

Ray, E. A., Moore, F. L., Rosenlof, K. H., Davis, S. M., Boenisch, H., Morgenstern, O., Smale, D., Rozanov, E., Hegglin, M., Pitari, G., Mancini, E., Braesicke, P., Butchart, N., Hardiman, S., Li, F., Shibata, K., and Plummer, D. A.: Evidence for changes in stratospheric transport and mixing over the past three decades based on multiple data sets and tropical leaky pipe analysis, J. Geophys. Res., 115, D21304, doi:10.1029/2010JD014206, 2010.

Severinghaus, J. P. and Battle, M. O.: Fractionation of gases in polar ice during bubble close-off: New constrains from firn air Ne, $\mathrm{Kr}$ and Xe observations, Earth Planet. Sci. Lett., 244, 474-500, 2006.

Severinghaus, J. P., Grachev, A., and Battle, M.: Thermal fractionation of air in polar firn by seasonal temperature gradients, Geochem. Geophys. Geosys., 2, 1048, doi:10.1029/2000GC000146, 2001.

Stiller, G. P., Von Clarmann, T., Haenel, F., Funke, B., Glatthor, N., Grabowski, U., Kellmann, S., Kiefer, M., Linden, A., Lossow, S., and López-Puertas, M.: Observed temporal evolution of global mean age of stratospheric air for the 2002 to 2010 period, Atmos. Chem. Phys., 12, 3311-3331, doi:10.5194/acp-12-3311-2012, 2012.

Waugh, D. W. and Hall, T. M.: Age of stratospheric air: Theory, observations, and models. Rev. Geophys., 40, 1010, doi:10.1029/2000RG000101, 2002. 